\title{
Towards a Sustainable Life: Smart and Green Design in Buildings and Community
}

\author{
Mi Jeong Kim (1) and Han Jong Jun * \\ School of Architecture, Hanyang University, Seoul 04763, Korea; mijeongkim@hanyang.ac.kr \\ * Correspondence: hanjong@hanyang.ac.kr
}

check for updates

Citation: Kim, M.J.; Jun, H.J. Towards a Sustainable Life: Smart and Green Design in Buildings and Community. Sustainability 2021, 13, 1022. https://doi.org/10.3390/su 13031022

Received: 13 January 2021

Accepted: 16 January 2021

Published: 20 January 2021

Publisher's Note: MDPI stays neutral with regard to jurisdictional claims in published maps and institutional affiliations.

Copyright: (c) 2021 by the authors. Licensee MDPI, Basel, Switzerland. This article is an open access article distributed under the terms and conditions of the Creative Commons Attribution (CC BY) license (https:// creativecommons.org/licenses/by/ $4.0 /)$.
Sustainability has been a popular topic among researchers in various disciplines since its value is critical to the development of user-centered environments and populations' wellbeing. The term sustainable development was introduced by the UN as "development that meet the needs of the present without compromising the ability of future generations to meet their own needs" [1], so it often means minimizing negative impacts on the environment or decreasing the consumption of resources for maintaining the environment's stability. Green or ecological designs are often used interchangeably with environmental sustainability in the architecture domain.

The concept of sustainability extends to development related to smart buildings and healthy communities, which could support sustainable living, meeting human needs and ensuring equity. For example, sustainable living can be achieved through the adoption of smart technologies into our living spaces, wherein intelligent computing could support people's activities, or the adoption of advanced systems into our community, wherein inhabitants' wellbeing could be promoted. Furthermore, maximizing energy efficiency or intuitive interaction with technologies could enhance occupants' optimal and positive experiences in our environment.

This Special Issue aims to include contributions on occupants' sustainable living in buildings and communities, highlighting issues surrounding the sustainable development of our environments and lives by emphasizing smart and green design perspectives. After a rigorous review of the submissions by experts, fourteen articles concerning sustainable living and development have been published in this Special Issue, by authors sharing their expertise and approaches to the concept and application of sustainability in their fields. The fourteen contributions to this special issue can be categorized into four groups, depending on the issues that they address.

The first group is interested in the spatial aspect of buildings and the use of design elements to implement sustainable architecture. Rather than relying on emerging technologies for development, they seek to identify the crucial factors related to sustainability from green perspectives and apply them to the built environment to achieve an eco-friendly and sustainable lifestyle.

Lee (Contribution 1) establishes a theoretical framework for sustainable architecture from a spatial perspective. He analyzes three sustainable buildings recognized by LEED (Leadership in Energy and Environmental Design) as case studies by using an analytical tool, a visibility graph in space syntax, with a focus on economic issues. It is found that sustainable architecture can be seen to configure forms in a spatially economic way. Lee reinterprets sustainable architecture syntactically as economical-technologically, environmentally, and spatially. Similarly, Lee and Oh (Contribution 2) investigate sustainable design alternatives, such as the layout of a building complex and the width-to-depth ratios of floorplans, in terms of their energy efficiency using a simulation program. The results indicate that the shape of a building is an important design factor for the optimization of energy use in residential building complexes. For example, square housing units produce higher energy costs than the typical long and rectangular type. With a focus on climate, 
$\mathrm{Ju}$ and $\mathrm{Oh}$ (Contribution 3) examine the ways in which the climatic conditions have influenced the transformation of apartments in Korea and Singapore. They extract design elements and principles that have been transformed or continued from the vernacular house, which is still in use. They argue that housing culture tends to retain its identity and is important to ensure a comfortable home with the use of green design elements. Lee and Park (Contribution 4) also emphasize the potential of natural features as design elements for the optimal health and wellbeing of the elderly in smart homes. Their research suggests that smart homes for the elderly should be designed as high-quality living spaces, emphasizing biophilic experiences rather than mechanical achievement since the elderly's inherent preference for nature could be strengthened by biophilic design.

Contrary to the first group, the second group emphasizes the potential of smart technologies for sustainable design and development in buildings and the community. Most authors actively utilize advanced technologies, such as artificial intelligence (AI) and virtual reality (VR), in simulating conditions to identify the effects of specific factors on inhabitants or building performance. Based on the results of the simulation, architects are expected to make a design decision effectively and efficiently for sustainable development.

Yi (Contribution 5) proposes a computational framework to evaluate adaptive human behavior and dynamic building performance with a focus on space occupancy, energy use, and generative envelope design. The proposed simulation platform involves an agentbased model with an AI approach that can be used for design decision-making in smart architectural design, allowing designers to quickly explore various design options through the sustainable building design methodology. Hong et al. (Contribution 6) investigate the effects of human behavior simulation on the usability factors of social sustainability in architectural design education. The motivation for this research is that factors of social sustainability are not often reflected in students' projects and there is a potential for the applicability of human behavior simulation to aid social sustainability centricity in architectural design. Human behavior simulation through VR promotes the performance of projects with respect to the parameters of accessibility and safety, ergonomic usability, and social interactions. Emphasizing the potential of the data as a reference for the future Crime Prevention Through Environmental Design (CPTED) evaluation criteria, Yang et al. (Contribution 7) measure environmental factors that affect street robbery decision-making through VR with eye-tracking technology. The study demonstrates the strength of a new methodology for assessing the factors affecting criminal decision-making from a criminal's perspective, verifying the measured data quantitatively in terms of accuracy and microlevel analysis.

The third group also utilizes technologies to articulate and enforce a user-oriented approach to sustainable design and development for improved living. They seek to develop effective methods for identifying factors that can affect users' positive emotions, preferences, and experiences in architectural design. The potential of the data reflecting users' perspectives is emphasized to support decision-making processes by architects and developers in architectural design.

Ji et al. (Contribution 8) use VR with electroencephalography data for the development of a deep-learning-based stress-ratio prediction model. They analyze the amount of stress changes in a virtual space by reconstructing Adolf Hitler's new Reich Chancellery using VR, synchronizing VR equipment, and measuring the electroencephalogram (EEG) signals. The result implies that, to achieve sustainable architectural designs, it is necessary to analyze the positive indices of certain architectural design elements through the linking processes of the EEG signals, which allow architects to effectively use the design elements that support occupants' positive emotions. Jun et al. (Contribution 9) present a housing recommendation system called "SeoulHouse2Vec," which maps users and items in embedding layers and uses public big data and GIS data to analyze housing preferences. They emphasize the proposed system's support for sustainability in that the recommendation system could enable rational decision-making in both housing consumption and supply, given that both are closely related to long-term personal, social, and environmental impacts. 
Zhen et al. (Contribution 10) classify intelligent design in terms of the "five senses" of interaction - visual, voice, tactile, cognitive, and emotional interaction - and explore how to embody such interactive experience design in smart building systems. They argue that the proposed principle of "user-oriented" interactive experience design can ensure the security, effectiveness, and sustainability of the smart building system.

The main issue addressed by the fourth group is the increase in equitable opportunities for all in our community, and concerns for social housing, water management, and the accessibility and wellness of disabled occupants and of workers are discussed. To ensure quality of life for all, the benefits of sustainable development should be extended to vulnerable people, such as those with low incomes, those in developing countries, those with disabilities and workers.

Chung et al. review the historical development and features of social housing and discuss policy implication with a focus on social housing in Seoul (Contribution 11). To enable the more sustainable provision of social housing in the future, they argue that four issues must be considered: the role of local governments in establishing suitable ordinances depending on situations, sustainable business models for social housing projects for the diversification of supply methods, the revitalization of community based on "social mix," and the cultivation of the capabilities of social housing providers through education on social economy, housing design, construction, operation, and finance. Park (Contribution 12) explores the connection between the ownership of water and water management in a divided territory-Cyprus-to obtain an understanding of how politics are involved in water conflict, emphasizing the importance of strategies for water distribution in a sustainable community. This research highlights possible future problems for cities and regions around world through the case study of Cyprus, with a vision for a sustainable water supply and the potential for future urbanization.

In 2018, the UN released a report on disability and sustainability: Realization of the Sustainable Development Goals by, for and with Persons with Disabilities [2]. Kim and Kim (Contribution 13) investigate the effects of disabled facilities on work safety, work satisfaction, and job retention among workers with disabilities in Korea. This research is meaningful in that it demonstrates the effects of workplace disability facilities on the effectiveness of workers with disabilities with external validity using national big data. The study argues that making workplaces more accessible is important to ensuring that disabled people are not left behind, thereby resulting in the sustainable development of our society. Hwang et al. (Contribution 14) evaluate the effects of a yoga program in reducing cardiovascular disease (CVD) risk factors in workers in small workplaces, based on the assumption that workers in small enterprises are particularly vulnerable in organized health management. They assigned a yoga intervention to their experiment group for 12 weeks and found that a yoga program could be a useful intervention for workers in reducing the physical measurements of CVD risk, such as waist circumstance and diastolic blood pressure. This result suggests that a yoga program may serve as a sustainable exercise strategy for workers in small enterprises.

This special issue specifically focuses on research and case studies that make efforts to develop promising methods for the sustainable development of our environment and to identify factors critical to the application of a sustainable paradigm for quality of life from a user-oriented perspective. This collection contains new research that provides insightful ideas, cognitive perspectives, and strategic approaches for the implementation of sustainability in architectural design, energy use, housing supply, crime prevention, the workplace, and the community. All the proposed methods, models, and applications in these studies contribute to the current understanding of the adoption of the sustainability paradigm and are likely to inspire further research addressing the challenges related to constructing sustainable buildings and community, resulting in a sustainable life for all of society. 


\section{List of Contributions}

1. Lee, J.H. Reinterpreting Sustainable Architecture: What Does It Mean Syntactically? Sustainability 2020, 12, 6566.

2. Lee, S.Y.; Oh, M.W. Sustainable Design Alternatives and Energy Efficiency for Public Rental Housing in Korea. Sustainability 2020, 12, 8456.

3. Ju, S.R.; Oh, J.E. Design Elements in Apartments for Adapting to Climate: A Comparison between Korea and Singapore. Sustainability 2020, 12, 3244.

4. Lee, E.J.; Park, S.J. A Framework of Smart-Home Service for Elderly's Biophilic Experience. Sustainability 2020, 12, 8572.

5. Yi, H. Visualized Co-Simulation of Adaptive Human Behavior and Dynamic Building Performance: An Agent-Based Model (ABM) and Artificial Intelligence (AI) Approach for Smart Architectural Design. Sustainability 2020, 12, 6672.

6. Hong, S.W.; Kim, H.; Song, Y.; Yoon, S.H.; Lee, J. Effects of Human Behavior Simulation on Usability Factors of Social Sustainability in Architectural Design Education. Sustainability 2020, 12, 7111.

7. Yang, J.W.; Kim, D.; Jung, S. Eye-Tracking Technology to Measure Environmental Factors Affecting Street Robbery Decision-Making in Virtual Environments. Sustainability 2020, 12, 7419 .

8. Ji, S.Y.; Kang, S.Y.; Jun, H.J. Deep-Learning-Based Stress-Ratio Prediction Model Using Virtual Reality with Electroencephalography Data. Sustainability 2020, 12, 6716.

9. Jun, H.J.; Kim, J.H.; Rhee, D.Y.; Chang, S.W. "SeoulHouse2Vec": An EmbeddingBased Collaborative Filtering Housing Recommender System for Analyzing Housing Preference. Sustainability 2020, 12, 6964.

10. Li, Z.; Zhang, J.; Li, M.; Huang, J.; Wang, X. A Review of Smart Design Based on Interactive Experience in Building Systems. Sustainability 2020, 12, 6760.

11. Chung, S.H.; Kim, S.J.; Park, S.Y.; Kim, J.H. Past, Present, and Future of Social Housing in Seoul: Where Is Social Housing Heading to? Sustainability 2020, 12, 8165.

12. Park, E.J. Strategy of Water Distribution for Sustainable Community: Who Owns Water in Divided Cyprus? Sustainability 2020, 12, 8978.

13. Kim, E.J.; Kim, I.; Kim, M.J. The Impact of Workplace Disability Facilities on Job Retention Wishes among People with Physical Disabilities in South Korea. Sustainability 2020, 12, 7489 .

14. Hwang, W.J.; Kim, J.A.; Ha, J.S. Effects of a Yoga Program in Reducing Cardiovascular Disease Risk Factors in Workers of Small Workplaces: A Pilot Test. Sustainability 2020, 12, 10038 .

Author Contributions: Conceptualization, M.J.K. and H.J.J; formal analysis, M.J.K.; writingoriginal draft preparation, M.J.K.; writing—review and edition, M.J.K. and H.J.J. All authors have read and agreed to the published version of the manuscript.

Funding: This work was supported by the National Research Foundation of Korea (NRF) grant funded by the Korea government (MSIT) (No. NRF-2019R1A2C1087344).

Institutional Review Board Statement: Not applicable.

Informed Consent Statement: Not applicable.

Data Availability Statement: The data presented in this study are available on request from the corresponding author. The data are not publicly available due to the policy of research projects.

Conflicts of Interest: The authors declare no conflict of interest.

\section{References}

1. Brundtland Commission. Our Common Future: The World Commission on Environment and Development; Oxford University Press: New York, NY, USA, 1987.

2. United Nations. Realization of the Sustainable Development Goals by, for and with Persons with Disabilities. Available online: https:/ / www.un.org/development/desa/disabilities/wp-content/uploads/sites/15/2018/12/Executive-Summary11.29-2.pdf (accessed on 10 January 2021). 